\title{
Stimulus-response compatibility in the programming of speech
}

\author{
DAVID A. ROSENBAUM \\ Hampshire College and University of Massachusetts, Amherst, Massachusetts \\ and \\ ANDREW M. GORDON, NEIL A. STILLINGS, and MARK H. FEINSTEIN \\ Hampshire College, Amherst, Massachusetts
}

\begin{abstract}
Subjects chose between sequences of one syllable (e.g., /gi/ vs. /bi/), two syllables (e.g., /gibi/ vs. /gubu/), and three syllables (e.g., /gibidi/ vs. gubudu/), when /i/ sequences were signaled by high-pitched tones and $/ \mathrm{u} /$ sequences were signaled by low-pitched tones (high compatibility), or the reverse (low compatibility). Choice times were additively affected by sequence length and compatibility. A second experiment showed attenuated compatibility effects for sequences with different vowels in the first and second syllables. These results replicate previously reported results for choices between finger sequences, which suggests that the same programming methods are used in both output domains. Evidently, choices between response sequences can be achieved by selecting a distinguishing parameter and assigning it in a serial fashion to partially prepared motor subprograms.
\end{abstract}

An emerging view of human movement control holds that abstract parameters are used in the programs for forthcoming movement sequences. For example, abstract timing information for movement sequences has been inferred from the fact that typing (Terzuolo \& Viviani, 1980), writing (Viviani \& Terzuolo, 1980), arm positioning (Armstrong, 1970; Shapiro, 1977), and walking (Shapiro, Zernicke, Gregor, \& Diestel, 1981) exhibit invariant timing relationships among successive movement elements (see Rosenbaum, 1985; Schmidt, 1975). Similar sorts of invariances for force (Freund \& Budingen, 1978; Ghez, 1979) have led to the proposal that force is another abstract parameter used in motor programming (Meyer, Smith, \& Wright, 1982).

Discovering abstract programming parameters raises the question of how the parameters are set during the programming process. Inhoff, Rosenbaum, Gordon, and Campbell (1984) addressed this question by conducting choice reaction-time (RT) experiments in which subjects chose between two homologous (mirror-image) finger sequences cued by signals that were either compatibly or incompatibly mapped to the hands performing the sequences. Stimulus-response (S-R) compatibility was

This paper is based on a Division III examination (equivalent to a senior honors thesis) by the second author and submitted to Hampshire College in partial fulfillment of the bachelor's degree. The research was supported in part by Grants BNS-8120104 and BNS-8408634 from the National Science Foundation and Research Career Development Award $1 \mathrm{KO4}$ NSOO942-01 from the National Institute of Neurological and Communicative Disorders and Stroke to the first author. We thank Alice Healy, David Meyer, Lynne Baker-Ward, Judith Kroll, and an anonymous reviewer for helpful comments. Correspondence should be addressed to David A. Rosenbaum, School of Communications and Cognitive Science, Hampshire College, Amherst, MA 01002 manipulated by assigning the signal on the left to the left hand and the signal on the right to the right hand (high S-R compatibility), or the opposite (low S-R compatibility). In the first experiment, S-R compatibility and the length of the to-be-performed sequence had additive effects on the choice RT for the first response, and latencies of noninitial responses were unaffected by S-R compatibility. Inhoff et al. suggested that subjects prepared for the choice by readying a motor program with instructions for a sequence of finger types (e.g., ring-middleindex) but with hand (right-left) information missing. When the reaction signal was identified, a single decision was made about whether the readied finger sequence was to be performed with the left or right hand, and execution of the sequence followed. Inhoff et al. called this process distributive parameter assignment, by analogy to the distributive property of multiplication [e.g., $a(x+y)$ $=a x+a y]$.

Two additional experiments provided further support for the distributive assignment hypothesis. These experiments compared sequences performed with only one hand (homogeneous sequences) with sequences that began with one hand and ended with the other (heterogeneous sequences). In both experiments, choice RT was affected not only by the S-R compatibility between the signal and first response but also by the compatibility between the signal and later responses in the sequences to be performed. This result suggests that the additive relation between sequence length and S-R compatibility, obtained in the first experiment, was not simply due to the fact that S-R compatibility extended to the first response alone.

In the present experiments, we apply the logic of Inhoff et al. (1984) to the analysis of speech production. 
Two principal questions underlie our investigation. One is whether the effects observed for manual responses apply to speech. If common principles characterize programming across a range of motor subsystems (Ostry \& Cooke, 1987; Sternberg, Monsell, Knoll, \& Wright, 1978), we would expect similar programming in the two domains. In particular, if the programming of vocal responses can use distributive assignments of single vowels to strings of consonants, the results of our speech production experiments should mirror the results of the manual production experiments of Inhoff et al. Thus, we should obtain additive effects of sequence length and S-R compatibility, and we should find influences of noninitial syllables on S-R compatibility effects observed at the first syllable.

The other question underlying this study concerns the relation between speech production and perception. According to the view that these two activities share common mechanisms-whether speech perception relies on an articulatory code (Liberman, Cooper, Shankweiler, \& Studdert-Kennedy, 1967) or articulation relies on a perceptual representation (Ladefoged, DeClerk, Lindau, \& Papçun, 1972) - choice RTs for speech should be affected by the relation between what is heard and what is said. Support for this prediction has recently been obtained by Gordon and Meyer (1984). In these studies, subjects produced one of four syllable-pairs (e.g., /puh-puh/ or /buh-duh/ or /duh-tuh/ or /tuh-buh/) in response to synthetic monosyllables with different initial consonants (e.g., /buh/ or /puh/). The main question was how the RT to produce a sequence depended on the phonological relation between the initial consonant of the sequence and the signal to which the sequence was assigned. Gordon and Meyer (1984) found that choice RTs were reduced by about $\mathbf{4 0} \mathrm{msec}$ if the heard and spoken consonants shared the feature of voicing.

The experiments reported here differed from the Gordon and Meyer (1984) experiments in several respects. First, our subjects chose between two sequences at a time, not four. Second, as has already been mentioned, our subjects produced sequences with varying numbers of syllables. Previous studies have shown that the RT to initiate a sequence of vocal responses increases with the number of syllables (Klapp, 1974) or stress groups (Sternberg et al., 1978) to be produced. We sought to replicate this finding and see how it depends on S-R compatibility. The third way in which our study differed from the work of Gordon and Meyer (1984) was that our subjects chose between vocal responses with common initial consonants and different succeeding vowels; in Gordon and Meyer's studies, some response alternatives had different initial consonants. The vowels we used were $/ \mathrm{i} /$, which has a subjectively high pitch, and / $\mathrm{u} /$, which has a subjectively lower pitch. ${ }^{1}$ We hypothesized that if pitch is part of an internal representation of vowels, sequences containing /i/ should be initiated more quickly when cued by highpitched signals than by low-pitched signals, and sequences containing $/ \mathrm{u} /$ should be initiated more quickly when cued by low-pitched signals than by high-pitched signals. Other, more detailed predictions were based on this expectation.

\section{EXPERIMENT 1}

In Experiment 1 subjects chose between sequences consisting of one, two, or three syllables. In the one-syllable condition the choice was /gi/ versus /gu/, in the twosyllable condition the choice was /gibi/versus /gubu/, and in the three-syllable condition the choice was /gibidi/ versus /gubudu/. Note that a single vowel, /i/ or / $/$ /, distinguished the choices in each condition. As mentioned above, we predicted that sequences with /i/ would be signaled more effectively by a high-pitched tone than by a low-pitched tone, and that sequences with $/ u /$ would be signaled more effectively by a low-pitched tone than by a high-pitched tone. We also predicted that if the choice between sequences is achieved in a single decisionnamely, by deciding between /i/ and / $\mathrm{u}$ - -the S-R compatibility effect should be independent of sequence length, provided that only the speed of the $/ \mathrm{i} /-/ \mathrm{u} /$ decision is affected by S-R compatibility (Sternberg, 1969). On the other hand, if the choice between sequences is achieved in a series of decisions concerning the identity of each syllable, the $S-R$ compatibility effect should increase with the length of the sequence to be produced, provided all the decisions are made before production of the sequence begins.

\section{Method}

Subjects. Eight Hampshire College students, all native speakers of English, served as volunteer subjects.

Procedure. Before each block of trials, the experimenter specified the response choices and their corresponding reaction signals. The two signals were 800 -and $1100-\mathrm{Hz}$ square-wave tones produced by an Apple IIt computer for $20 \mathrm{msec}$. The tones were selected informally to be easily categorized as "high" and "low." Subjects' responses were detected with a Shure microphone (Model 575S) and a Gerbrands voice key (Model G1341). The latency of response was recorded to the nearest millisecond by the computer, under the control of a Cognitive Testing Station (Digitry Corporation, Medford, MA). Because of technical limitations, only the onset times were recorded.

After the subject made the response, the experimenter judged its accuracy and entered an accuracy score into the comptuer. The next tone was presented $1 \mathrm{sec}$ later.

Feedback was presented at the end of each block of trials. It consisted of a list of RTs for each trial in the block, the mean RT, and the number of correct responses. Subjects were instructed to strive for consistently short RTs and consistently high accuracy.

Design. Each choice condition was tested in two consecutive blocks of 20 trials each. The selection of stimuli from trial to trial was random. For each subject, after all conditions were tested once, the entire sequence was repeated in the same order within the same 1 -h session. All subjects participated in all six conditions. The order in which the 8 subjects were tested in the six conditions minimized the number of times that any given condition followed any other condition as well as the number of times that each condition appeared in a given serial position within the testing cue. 


\section{Results}

Errors occurred on $8.7 \%$ of the trials in the first half of the session and on $3.2 \%$ of the trials in the second half of the session. Of the errors that occurred in the first half of the session, $52 \%$ were made in the incompatible S-R mapping conditions, and of the errors that occurred in the second half of the session, $73 \%$ were made in the incompatible S-R mapping conditions.

Mean choice RTs are shown in Figure 1. A repeated measures analysis of variance (ANOVA) tested the effects of vowel $(/ \mathrm{i} /$ or $/ \mathrm{u} /$ ), sequence length (one, two, or three syllables), signal (high or low), and session half. Nonsignificant effects were obtained for signal $[F(1,7)=$ $1.51, p>.25]$ and vowel $[F(1,7)<1]$, but there was a significant effect of sequence length $[F(2,14)=4.33$, $p<.04]$ and a significant interaction between vowel and signal $[F(1,7)=15.84, p<.01]$ such that $/ \mathrm{i} /$ responses were initiated $94 \mathrm{msec}$ more quickly when the signal was the high tone rather than the low tone and $/ \mathrm{u} /$ responses were initiated $78 \mathrm{msec}$ more quickly when the signal was the low tone rather than the high tone; the latter result is an S-R compatibility effect. The interaction between sequence length, vowel, and signal did not approach statistical significance $[F(2,14)<1]$. The main effect of session half was large $[F(1,7)=63.13, p<.001]$; mean RTs were 356 and $266 \mathrm{msec}$ in the first and second halves of the session, respectively. There was a marginally significant interaction between session half and length $[F(2,14)=2.88, p<.09]$; mean RTs for the one-, two-, and three-syllable sequences were 341,335 , and $390 \mathrm{msec}$

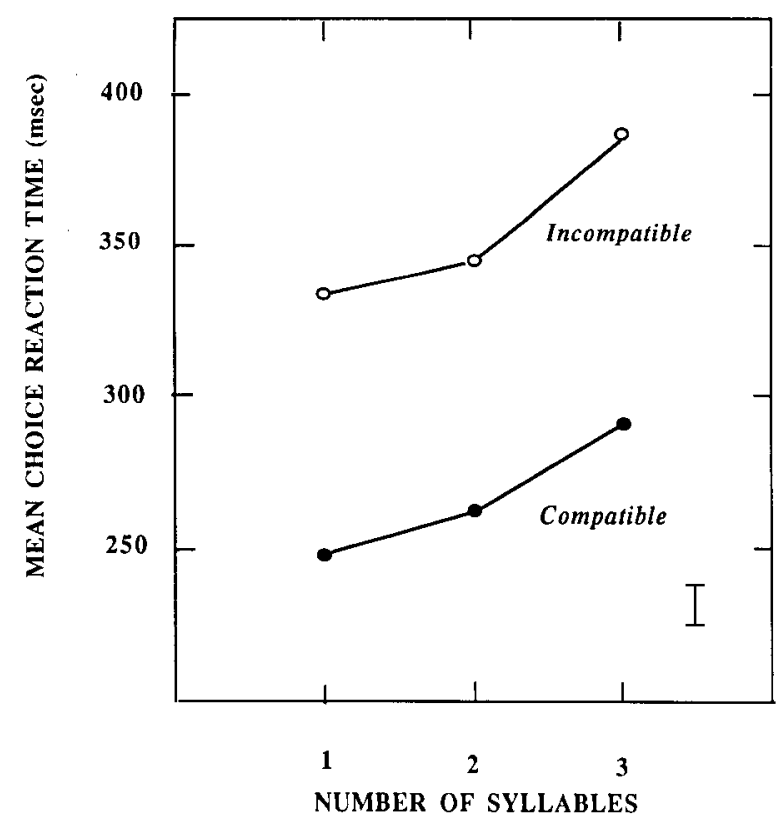

Figure 1. Mean choice reaction times for one-, two-, and threesyllable sequences in conditions of high or low stimulus-response compatibility. Each point represents the mean of approximately $640 \mathrm{ob}-$ servations. Estimate of \pm 1 standard error is based on between-subject differences. Data are from Experiment 1. in the first half of the session, and 239, 273, and $284 \mathrm{msec}$ in the second half of the session. There was a significant interaction between session half, signal, and vowel $[F(1,7)=7.17, p<.04]$. In the first half of the session, the benefit of pairing the high tone with the high vowel as opposed to the low vowel was $111 \mathrm{msec}$, and the benefit of pairing the low signal with the low vowel as opposed to the high vowel was $115 \mathrm{msec}$; however, in the second half of the session, the benefit of pairing the high tone with the high vowel as opposed to the low vowel was $68 \mathrm{msec}$, and the benefit of pairing the low signal with the low vowel as opposed to the high vowel was $53 \mathrm{msec}$. No other interactions in this ANOVA approached statistical significance; all remaining $p$ values exceeded .30.

Another ANOVA evaluated S-R compatibility, sequence length, and practice (first or second half of the session). ${ }^{2}$ The interaction between sequence length and S-R compatibility was not statistically significant $[F(2,7)<1]$, although the main effects of sequence length $[F(2,14)=4.42, p<.04]$ and S-R compatibility $[F(1,7)=16.59, p<.005]$ were. Mean RTs were significantly shorter in the second half of the session than in the first half $[F(1,7)=61.23, p<.001]$, and, consistent with the results of the preceding ANOVA, incompatible conditions improved more from the first to the second half of the session than did compatible conditions $[F(1,7)=6.24, p<.05]$. There was a marginally significant interaction between session half and sequence length $[F(2,14)=2.86, p<.10]$, but no other interactions approached statistical significance (all $p \mathrm{~s}>.50$ ).

\section{Discussion}

The results of Experiment 1 indicate that the time to initiate one of two possible vocal response sequences is independently affected by sequence length and S-R compatibility. The effect of sequence length replicates Klapp (1974) and Sternberg et al. (1978) ${ }^{3}$ The S-R compatibility effect qualitatively replicates Gordon and Meyer (1984), although our S-R compatibility effect (113 msec in the first half of the session and $61 \mathrm{msec}$ in the second half of the session) is larger than the one they reported. Evidently, the time to produce a consonant-vowel syllable is powerfully affected by the relationship between the pitch of the vowel and the pitch of the tone that signals it. This effect may be categorical (i.e., based on a "high"-"low" label distinction) rather than physical (i.e., based on absolute pitch matching), because the effect did not differ in any systematic way for subjects with high- or low-pitched speaking voices.

The independence of sequence length and S-R compatibility replicates the result of Inhoff et al. (1984) for choices between left- and right-hand manual response sequences with varying numbers of finger responses and with choice signals presented to one side or the other. Inhoff et al. attributed their results to distributive assignment of a single abstract feature (hand) to prepared subprograms for finger responses. The present results suggest that the same sort 
of process applies to speech programming, with vowel being the abstract feature that can be distributively assigned to an ordered list of consonants.

\section{EXPERIMENT 2}

If aspects of a forthcoming response sequence are distributively assigned to the entire sequence, the time to initiate the sequence should be affected not only by the compatibility of the choice signal and first response, but also by the compatibility between the choice signal and later responses. Recall that Inhoff et al. (1984) tested this prediction by using manual sequences that began with one hand and ended with the other. They found that the effects of S-R compatibility on the time for the first response depended on the compatibility between the reaction signal and noninitial as well as initial responses. This result supported the distributive assignment hypothesis and also helped rule out the hypothesis that subjects merely decided between the two first responses and then produced the sequence corresponding to the response that was selected. In the present study, it was equally important to rule out this hypothesis.

By analogy to Inhoff et al. (1984), in Experiment 2 we used two-syllable sequences that had either the same vowel in the first and second syllables (homogeneous sequences) or different vowels in the first and second syllables (heterogeneous sequences). We predicted that heterogeneous sequences would show smaller S-R compatibility effects than would homogeneous sequences. For example, we predicted that the effect of signaling /bubi/ with a highor low-pitched tone would be smaller than the effect of signaling /bibi/ with a high- or low-pitched tone.

Table 1 lists the choices used in the experiment. There were two groups of subjects. For one group, one of the responses was always the homogeneous sequence / $\mathrm{bibi} /$; for the other group, one of the responses was always the homogeneous sequence /bubu/. In Conditions A1 and A2, each group chose between their constant response and the other homogeneous sequence. Thus, for the / bibi/group, the response alternative was $/ \mathrm{bubu} /$, whereas for the /bubu/ group, the response alternative was /bibi/. For both groups, compatible S-R mappings were used in Condition $\mathrm{A} 1$ and incompatible $S-R$ mappings were used in Condition A2.

In Conditions B1 and B2, the constant responses were paired with heterogeneous sequences. Thus, /bibi/ was paired with /bubi/, and /bubu/ was paired with /bibu/. Condition Bl used compatible S-R mappings, and Condition $\mathbf{B} 2$ used incompatible S-R mappings. Note that in both of the $B$ conditions the constant and alternative responses had different vowels in the first syllable only.

In Conditions $\mathrm{C} 1$ and $\mathrm{C} 2$, the constant responses were paired with heterogeneous sequences whose distinguishing vowel occupied the second syllable only. Thus, /bibi/ was paired with / $/ \mathrm{bibu} /$, and $/ \mathrm{bubu} /$ was paired with $/ \mathrm{bubi} /$. By comparing Condition C to Condition B, we could determine whether the time to choose between two utterances was reduced if the vowel distinguishing the utterances was in Syllable 2 instead of Syllable 1. Previous studies of manual sequence performance (Rosenbaum, Hindorff, \& Munro, 1986, 1987; Rosenbaum, Inhoff, \& Gordon, 1984) have shown that choice RTs decrease as the serial position of the first difference between sequences recedes from the beginning of the sequence toward the end. If this phenomenon applies to speech, we would expect reaction times in Condition $\mathrm{C}$ to be shorter than in Condition B.

In Condition $\mathrm{C}$, as in the other conditions of this experiment, we manipulated the mapping of signals to responses. This manipulation allowed us to address the question of whether vowel-based S-R compatibility effects are due to the relation between the reaction signal and the vowel that is about to be physically produced (the

Table 1
Choices, Mean Reaction Times (RTs), and Standard Errors of Reaction Times (Both in Milliseconds) in Experiment 2

\begin{tabular}{|c|c|c|c|c|c|c|c|}
\hline Condition & $\begin{array}{c}\text { Type of } \\
\text { Alternative Response }\end{array}$ & $\begin{array}{c}\text { Position(s) of } \\
\text { Vowel Difference }\end{array}$ & $\begin{array}{c}\text { S-R } \\
\text { Compatibility } \\
\end{array}$ & $\begin{array}{l}\text { High-Tone } \\
\text { Sequence }\end{array}$ & $\begin{array}{l}\text { Low-Tone } \\
\text { Sequence }\end{array}$ & Mean RT & $\begin{array}{l}\text { Standard } \\
\text { Error }\end{array}$ \\
\hline \multicolumn{8}{|c|}{ Group 1 (Constant Response $=/ \mathrm{bibi} /)$} \\
\hline $\begin{array}{l}\mathrm{A} 1 \\
\mathrm{~A} 2\end{array}$ & Homogeneous & $1 \& 2$ & $\begin{array}{l}\text { High } \\
\text { Low }\end{array}$ & $\begin{array}{l}\text { bibi }(217) \\
\text { bubu (384) }\end{array}$ & $\begin{array}{l}\text { bubu }(259) \\
\text { bibi }(359)\end{array}$ & $\begin{array}{l}238 \\
372\end{array}$ & $\begin{array}{l}19 \\
16\end{array}$ \\
\hline $\begin{array}{l}\text { B1 } \\
\text { B2 }\end{array}$ & Heterogeneous & 1 & $\begin{array}{l}\text { High } \\
\text { Low }\end{array}$ & $\begin{array}{ll}\text { bibi } & (240) \\
\text { bubi } & (327)\end{array}$ & $\begin{array}{l}\text { bubi }(275) \\
\text { bibi }(328)\end{array}$ & $\begin{array}{l}258 \\
328\end{array}$ & $\begin{array}{l}13 \\
17\end{array}$ \\
\hline $\begin{array}{l}\mathrm{C} 1 \\
\mathrm{C} 2\end{array}$ & Heterogeneous & 2 & $\begin{array}{l}\text { High } \\
\text { Low }\end{array}$ & $\begin{array}{ll}\text { bibi } & (213) \\
\text { bibu } & (314)\end{array}$ & $\begin{array}{l}\text { bibu }(262) \\
\text { bibi }(356)\end{array}$ & $\begin{array}{l}238 \\
334\end{array}$ & $\begin{array}{l}13 \\
17\end{array}$ \\
\hline \multicolumn{8}{|c|}{ Group $2($ Constant Response $=/$ bubu $/)$} \\
\hline $\begin{array}{l}\mathrm{A} 1 \\
\mathrm{~A} 2\end{array}$ & Homogeneous & $1 \& 2$ & $\begin{array}{l}\text { High } \\
\text { Low }\end{array}$ & $\begin{array}{l}\text { bibi }(259) \\
\text { bubu }(390)\end{array}$ & $\begin{array}{l}\text { bubu }(280) \\
\text { bibi }(357)\end{array}$ & $\begin{array}{l}270 \\
374\end{array}$ & $\begin{array}{l}19 \\
14\end{array}$ \\
\hline $\begin{array}{l}\mathrm{B} 1 \\
\mathrm{~B} 2\end{array}$ & Heterogeneous & 1 & $\begin{array}{l}\text { High } \\
\text { Low }\end{array}$ & $\begin{array}{l}\text { bibu }(268) \\
\text { bubu }(341)\end{array}$ & $\begin{array}{l}\text { bubu }(270) \\
\text { bibu }(350)\end{array}$ & $\begin{array}{l}269 \\
346\end{array}$ & $\begin{array}{l}14 \\
18\end{array}$ \\
\hline $\begin{array}{l}\mathrm{C} 1 \\
\mathrm{C} 2\end{array}$ & Heterogeneous & 2 & $\begin{array}{l}\text { High } \\
\text { Low }\end{array}$ & $\begin{array}{l}\text { bubi }(274) \\
\text { bubu }(332)\end{array}$ & $\begin{array}{l}\text { bubu }(276) \\
\text { bubi }(330)\end{array}$ & $\begin{array}{l}275 \\
331\end{array}$ & $\begin{array}{l}11 \\
14\end{array}$ \\
\hline
\end{tabular}


production view), or the relation between the reaction signal and the vowel being selected for subsequent production (the selection view). If the production view is correct, S-R compatibility should be defined by the relation between the signal and the vowel in the first syllable, in which case the mean RT for /bibu/ should be shorter when a high signal is presented than when a low signal is presented (when the alternative is / bibi/), and the mean RT for /bubi/ should be shorter when a low signal is presented than when a high signal is presented (when the alternative is /bubu/). On the other hand, if the selection view is correct, S-R compatibility should be defined by the relation between the signal and vowel in the second syllable, in which case the opposite prediction would be made. Thus, the mean RT for /bibu/ should be longer when a high signal is presented than when a low signal is presented (when the alternative is / bibi/), and the mean RT for /bubi/ should be longer when a low signal is presented than when a high signal is presented (when the alternative is /bubu/).

\section{Method}

Four Hampshire College students served as subjects in each of the two groups. As in Experiment 1, each of the six conditions was tested in two consecutive blocks of 20 trials each. After a subject completed all six conditions, he/she was tested again in the six conditions in the same order as in the first half of the 1-h session. In all other respects, the design and procedure were the same as in Experiment 1.

\section{Results}

Errors occurred on $13 \%$ of the trials in the first half of the session and on less than $4 \%$ of the trials in the second half of the session. Mean RTs for individual utterances in the 12 choice conditions (see Table 1) were analyzed with an ANOVA that tested the effects of constantresponse group (/bibi/ or /bubu/), type of response (constant or varied), choice type (A, B, or C), mapping condition (compatible or incompatible), and practice (first or second half of the session). (Note that on the basis of the clear trends in the data, we decided that in Condition $\mathrm{C}$, $/ \mathrm{bibu} /$ paired with a high tone should be classified as incompatible and /bubi/ paired with a low tone should be classified as incompatible.)

The effect of mapping condition was highly significant $[F(1,6)=15.58, p<.007]$. As seen in Table 2 , which collapses across responses, groups, and session halves, the mean RT of the compatible mapping conditions $(258 \mathrm{msec})$ was shorter than the mean RT of the incompatible mapping conditions $(347 \mathrm{msec})$. The interaction between type of choice and mapping condition was also significant $[F(2,13)=4.28, p<.05]$. As seen in Table 2 , the effect of S-R compatibility was attenuated in Conditions $B$ and $C$, which used heterogeneous sequences, as compared to that in Condition $A$, which used only homogeneous sequences. In Condition B the compatibility effect was $73 \mathrm{msec}$, in Condition $C$ the compatibility effect was $76 \mathrm{msec}$, but in Condition A the compatibility effect was $119 \mathrm{msec}$.

In addition to the above effects, there was a significant interaction between response (constant or varied) and mapping condition $[F(1,6)=7.54, p<.04]$. The effect of mapping condition was larger by $66 \mathrm{msec}$ for the constant responses than for the varied responses. This difference was also unequal for the two groups of subjects, as reflected in a significant groups $\times$ response $\times$ mapping condition interaction. For the / $/ \mathrm{bibi} /$ group the compatibility effect was $48 \mathrm{msec}$ larger for the constant responses than for the varied responses, whereas for the /bubu/ group the compatibility effect was $83 \mathrm{msec}$ larger for the constant responses than for the varied responses. There was also a marginally significant interaction between groups and responses $[F(1,6)=5.39, p=.058]$. For the /bibi/ group the constant response had a shorter mean RT $(286 \mathrm{msec})$ than did the varied response $(304 \mathrm{msec})$, whereas for the /bubu/ group the constant response had a slightly longer mean RT ( $315 \mathrm{msec})$ than did the varied response (306 $\mathrm{msec})$.

There was a main effect of practice $[F(1,6)=9.83$, $p<.03$ ]; mean RTs were 63 msec longer in the second half of the session than in the first. Practice did not interact with any other factor, however; all corresponding $p$ values exceeded .25 . Similarly, no other interactions approached statistical significance in the analysis; all corresponding $p$ values exceeded .25 .

\section{Discussion}

Let us review these results in terms of the predictions that Experiment 2 was designed to test. First, there was a clear S-R compatibility effect. In general, sequences that began with a syllable containing a high-pitched vowel (e.g., /bibi/) were produced more quickly when the reaction signal was a high-pitched tone than when the reac-

Table 2

Mean Reaction Times and Standard Errors from Experiment 2*

\begin{tabular}{|c|c|c|c|c|}
\hline $\begin{array}{c}\text { Type of } \\
\text { Alternative Response }\end{array}$ & $\begin{array}{c}\text { Position(s) of } \\
\text { Vowel Difference }\end{array}$ & $\begin{array}{c}\text { S-R } \\
\text { Compatibility }\end{array}$ & Mean RT & $\begin{array}{c}\text { Standard } \\
\text { Error }\end{array}$ \\
\hline Homogeneous & $1 \& 2$ & $\begin{array}{l}\text { High } \\
\text { Low }\end{array}$ & $\begin{array}{l}254 \\
372\end{array}$ & $\begin{array}{l}19 \\
17\end{array}$ \\
\hline Heterogeneous & 1 & $\begin{array}{l}\text { High } \\
\text { Low }\end{array}$ & $\begin{array}{l}264 \\
337\end{array}$ & $\begin{array}{l}14 \\
18\end{array}$ \\
\hline Heterogeneous & 2 & $\begin{array}{l}\text { High } \\
\text { Low }\end{array}$ & $\begin{array}{l}257 \\
333\end{array}$ & $\begin{array}{l}12 \\
16\end{array}$ \\
\hline
\end{tabular}

*All data are in milliseconds 
tion signal was a low-pitched tone; the opposite effect was obtained for sequences that began with a syllable containing a low-pitched tone (e.g., /bubu/).

The nature of the S-R compatibility effect in Condition $\mathrm{C}$ favors the selection view over the production view of S-R compatibility. Contrary to the production view, the RT for / bibu/ and for /bubi/ in Condition C was not facilitated by having the pitch of the reaction signal correspond to the pitch of the vowel in the first syllable. Rather, as predicted by the selection view, /bibu/ and /bubi/ were initiated more quickly when the pitch of the reaction signal corresponded to the vowel distinguishing each of these utterances from the utterance with which it was paired.

A third major result was that the magnitude of the S-R compatibility effect was larger for the homogeneous sequences than for the heterogeneous sequences. This result replicates the results of Inhoff et al. (1984) and extends those results to speech production. Finding attenuated S-R compatibility effects for heterogeneous sequences in the present experiment suggests that subjects in Experiment 1 did not choose between utterances by simply choosing between the first syllables of the two response alternatives.

The only result of Experiment 2 that did not clearly support one of our predictions was that there was only a small reduction in mean $R T$ s in Condition $C$ relative to those in Condition B. In Condition B the first syllable was always uncertain, but in Condition $C$ the first syllable was always certain and the second syllable was uncertain. With the first syllable certain, subjects in Condition C potentially could have preprogrammed the first syllable and thereby reduced their RTs. However, there was little or no evidence that they did so (or that if they did, it reduced RTs). The reason for this outcome is not entirely clear. One possibility is that because of coarticulatory effects in speech, full programming of the first syllable awaited specification of the vowel in the second syllable.

\section{GENERAL DISCUSSION}

The results of the present study parallel Inhoff et al.'s (1984) results on the programming of rapid finger sequences. Just as Inhoff et al. found that sequence length and S-R compatibility have additive effects on the choice $\mathrm{RT}$ for a finger sequence, we found an additive effect for speech (in Experiment 1). And just as Inhoff et al. found attenuated S-R compatibility effects for sequences that began with one hand and ended with the other, we found attenuated S-R compatibility effects for verbal sequences with different vowels in the first and second syllables (in Experiment 2). The similarities of the two sets of results suggest that similar methods of programming are used in the two domains. One programming method that appears common to speech and manual programming is the distributive assignment of features to the segments of readied programs.

Let us consider how distributive assignment works. We will do so by considering why the heterogeneous se- quences had attenuated S-R compatibility effects, both here and in the study of Inhoff et al. (1984). A natural way to account for the attenuated S-R compatibility effect is to assume that subjects first readied a program with all the features common to the two possible responses and that they then used the reaction signal to identify those features that could not be identified ahead of time. Once the features were identified, they were assigned serially and independently to each segment of the previously readied program. This model predicts additivity between S-R compatibility and sequence length (the main result of Experiment 1) as well as the attenuated S-R compatibility result of Experiment 2, provided one assumes that $\mathrm{S}-\mathrm{R}$ compatibility influences the time to choose the feature (or features) to be assigned but does not affect the time to actually carry out the assignments. In other words, the model asserts that the time $T$ to initiate one of two possible sequences is

$$
T=k+p c+q i+a u,
$$

where $k$ is a constant, $c$ is the time to choose a feature that is compatibly mapped to the reaction signal, $p$ is the number of such features, $i$ is the time $(i>c)$ to choose a feature that is incompatibly mapped to the reaction signal, $q$ is the number of such features, $a$ is the feature assignment time (which is independent of S-R compatibility), and $u$ is the number of subprograms requiring assignment (not necessarily the total number of responses in the sequence). Note that this model assumes distributive feature assignment in the sense that a feature that will be assigned to several program segments needs to be chosen only once, although it will be assigned to the program segments in a serial fashion.

The model accounts for the data as follows. In Experiment $1, p$ equaled 1 and $q$ equaled 0 when S-R compatibility was high, $p$ equaled 0 and $q$ equaled 1 when S-R compatibility was low, and $u$ grew with sequence length. Hence, $T$ grew with sequence length (which was perfectly correlated with $u$ ) at a fixed rate $a$, and the intercepts of the high-and low-compatibility functions differed by $i-c$. In Experiment 2, $p$ equaled 1 and $q$ equaled 0 when S-R compatibility was high, $p$ equaled 0 and $q$ equaled 1 when S-R compatibility was low, and $u$ equaled 1 in Conditions $B$ and $C$ (where only one vowel was uncertain) or 2 in Condition A (where two vowels were uncertain). The difference in $u$ accounts for the fact that mean RTs were longer in Condition A than in Conditions B and C, although the fact that this effect was restricted to the incompatible mapping conditions is somewhat problematic. (It is likely that subjects were biased to prepare the wellmapped sequences ahead of time, which would have made the RTs for those sequences insensitive to choice context effects.)

The serial assignment model also accounts for the results of Inhoff et al. (1984). It accounts for the additivity between sequence length and S-R compatibility obtained in Inhoff et al.'s first experiment in the same way that it accounts for the corresponding result of Experiment 1 
in the present study. The model accounts for the attenuated S-R compatibility effects observed by Inhoff et al. in their second and third experiments, because it says that in those experiments RTs included either the sum of two short feature selection times (in the high-compatibility choice between homogeneous sequences), the sum of two long feature selection times (in the low-compatibility choice between homogeneous sequences), or the sum of a short feature selection time and a long feature selection time (in the choice between heterogeneous sequences).

There are a couple of remaining issues for the serial assignment model that still have to be considered. One concerns the model's account of sequence length effects. The model says that RTs increase with sequence length because of increases in the number of program segments requiring feature assignment ( $u$ in the model). However, previous studies have shown that RTs increase with sequence length even in simple RT tasks (Sternberg et al., 1978), that is, where no feature assignments seem to be required, which implies that feature assignment is not the only source of sequence length effects. Of course, it is conceivable that some last-minute feature assignments are in fact required in simple RT tasks, in which case the model could apply there as well. However, interresponse times also increase with sequence length, and they do so more in the middle of the sequence than at the ends (Sternberg et al., 1978). The latter results have been explained using a hierarchical decoding model (Rosenbaum, 1985; Rosenbaum, Kenny, \& Derr, 1983), according to which the time to produce each element of a movement sequence, including the first element, depends on the number of nodes to be traversed between successive terminal nodes in a "tree" representing the sequence. As one of us has shown elsewhere (Rosenbaum, 1985), as the length of a sequence increases, the complexity of its program tree also increases, and so the average number of nodes to be traversed to get from the root of the tree to the first terminal node also increases. Assuming that each extra node traversal takes extra time, this model accounts for the fact that RT increases with sequence length. Furthermore, because more nodes tend to be traversed in the middle of the sequence than at the ends, interresponse times also tend to be longer in the middle of the sequence (see Rosenbaum, 1985, for details). The tree-traversal model handles sequence length effects quite well, therefore, although the serial assignment model proposed in this paper does so as well in more limited choice domains. An important question for future research will be to determine how the two models can be combined.

The second issue for the serial assignment model concerns the effects of the serial position of the choice point between two sequences. In Experiment 2 of the present study, RTs were equivalent whether the position of vowel difference was Syllable 1 or 2. This result is consistent with the serial assignment model because the model says that, in general, $T$ should not depend on the serial position of the difference between two response sequences (see Equation 1). Nevertheless, previous studies have found significant effects of choice position on RT. For example, in the second experiment of Inhoff et al. (1984), choice RTs for heterogeneous sequences were longer when the first choice point was resolved through an incompatible $S-R$ mapping than through a compatible $S-R$ mapping. In addition, Rosenbaum et al. $(1986,1987)$ and Rosenbaum et al. (1984) reported that choice RT decreased as the (single) choice point between two finger sequences receded from the beginning of the sequence toward the end. Establishing the exact mechanism responsible for the presence or absence of choice point effects will be another important topic for future investigations.

Apart from the processing issues surrounding this research, the S-R compatibility effects we have obtained have important implications for theories of speech production. In particular, the effects support the view that pitch is part of the representation of vowels and that pitch plays a role in decision making about which vowels to produce, even in highly practiced "nonsense" utterances where no use of phonological rules is apparently required. What is represented appears to be abstract or relative pitch, since the reaction signals we used were not keyed to actual, produced, formant frequencies. Moreover, the pitch feature can be invoked by a nonlinguistic auditory stimulus, which may indicate that this aspect of linguistic representation is not sealed off in a specialized speech module. The latter conclusion accords with the suggestion (Pisoni, 1978) that vowels are not processed in an exclusively linguistic processor.

\section{REFERENCES}

ARMSTRONG, T. R. (1970). Training for the production of memorized movement patterns (Tech. Rep. No. 26). Ann Arbor: University of Michigan, Human Performance Center.

Delattre, P., Liberman, A. M., Cooper, F. S., \& Gerstman, L. J. (1952). An experimental study of the acoustic determinants of vowel color: Observations on one- and two-formant vowels synthesized from spectrographic patterns. Word, 8, 195-210.

Freund, H. J., \& Budingen, H. J. (1978). The relationship between speed and amplitude of the fastest voluntary contractions of human arm muscles. Experimental Brain Research, 31, 1-12.

GHEz, C. (1979). Contribution of central programs to rapid limb movement in the cat. In H. Asanuma \& V. J. Wilson (Eds.), Integration in the nervous system. Tokyo: Igaku-Shoin.

Gordon, P. C., \& MEYER, D. E. (1984). Perceptual-motor processing of phonetic features in speech. Journal of Experimental Psychology: Human Perception \& Performance, 10, 153-178.

Inhoff, A. W., Rosenbaum, D. A., Gordon, A. M., \& Campbell, J. A. (1984). Stimulus-response compatibility and motor programming of manual response sequences. Journal of Experimental Psychology: Human Perception \& Performance, 10, 724-733.

KLAPP, S. T. (1974). Syllable-dependent pronunciation latencies in number naming: A replication. Journal of Experimental Psychology, 102, 1138-1140.

LADEFoged, P. (1975). A course in phonetics. New York: Harcourt Brace Jovanovich

Ladefoged, P., DeClerk, J., Lindau, M., \& Papçun, G. (1972). An auditory-motor theory of speech production. UCLA Working Papers in Linguistics, 22, 48-75.

Liberman, A. M., Cooper, F. S., Shankweiler, D. P., \& StuddertKennedy, M. G. (1967). Perception of the speech code. Psychological Review. 74, 431-461.

Meyer, D. E. Smith, J. E. K., \& Wright, C. E. (1982). Models for 
the speed and accuracy of aimed movements. Psychological Review, 89, 449-482.

MILLER, J. L. (1981), Effects of speaking rate on segmental distinctions. In P. D. Eimas \& J. L. Miller (Eds.), Perspectives on the study of speech (pp. 39-74). Hillsdale, NJ: Erlbuam.

OSTRY, D. J., \& COOKE, J. D. (1987). Kinematic patterns in speech and limb movements. In E. Keller \& M. Gopnik (Eds.), Motor and sensory language processes. Hillsdale, NJ: Erlbaum.

Peterson, G. E., \& Barney, H. L. (1952). Control methods used in a study of the vowels. Journal of the Acoustical Society of America, 8, 175-184.

PIsonI, D. B. (1978). Speech perception. In W. K. Estes (Ed.), Handbook of learning and cognitive processes (Vol. 6, pp. 167-233). Hillsdale, NJ: Erlbaum.

Rosenbaum, D. A. (1985). Motor programming: A review and scheduling theory. In H. Heuer, U. Kleinbeck, \& K.-M. Schmidt (Eds.), Motor behavior: Programming, control, and acquisition (pp. 1-33). Berlin: Springer-Verlag.

Rosenbaum, D. A., Hindorff, V., \& Munro, E. M. (1986). Programming of rapid finger sequences. In H. Heuer \& C. Fromm (Eds.), Generation and modulation of action patterns [Experimental Brain Research Series 15J (pp. 64-71). Berlin: Springer-Verlag.

Rosenbaum, D. A., HindorfF, V., \& Munro, E. M. (1987). Scheduling and programming of rapid finger sequences: Tests and elaborations of the hierarchical editor model. Journal of Experimental Psychology: Human Perception \& Performance, 13, 193-203.

Rosenbaum, D. A., INHOFF, A. W., \& Gordon, A. M. (1984). Choosing between movement sequences: A hierarchical editor model. Journal of Experimental Psychology: General, 113, 372-393.

Rosenbaum, D. A., KenNy, S., \& DeRR, M. A. (1983). Hierarchical control of rapid movement sequences. Journal of Experimental Psychology: Human Perception \& Performance, 9, 86-102.

ScHmidT, R. A. (1975). The schema as a solution to some persistent problems in motor learning theory. In G. E. Stelmach (Ed.), Motor control: Issues and trends (pp. 41-65). New York: Academic Press.

SHapiro, D. C. (1977). A preliminary attempt to determine the duration of a motor program. In D. M. Landers \& R. W. Christina (Eds.), Psychology of motor behavior and sport (Vol. 1, pp. 17-24). Urbana, IL: Human Kinetics.

Shapiro, D. C., Zernicke, R. F., Gregor, R. J., \& Diestel, J. D. (1981). Evidence for generalized motor programs using gait pattern analysis. Journal of Motor Behavior, 13, 33-47.

STERNBERG, S. (1969). The discovery of processing stages: Extensions of Donders' method. Acta Psychoiogica, 30, 276-315.

Sternberg, S., Monsell, S., Knoll, R. L., \& Wright, C. E. (1978). The latency and duration of rapid movement sequences: Compari- sons of speech and typewriting. In G. E. Stelmach (Ed.), Information processing in motor control and learning (pp. 117-152). New York: Academic Press.

Terzuolo, C., \& Viviani, P. (1980). Determinants and characteristics of motor patterns used for typing. Neuroscience, 5, 1085-1103.

VIVIANI, P., \& Terzuolo, C. (1980). Space-time invariance in learned motor skills. In G. E. Stelmach (Ed.), Tutorials in motor behavior (pp. 525-532). Amsterdam: North-Holland.

\section{NOTES}

1. Ladefoged (1975, p. 170) reported that typical first, second, and third formant frequencies are 280,2250 , and $2890 \mathrm{~Hz}$, respectively, for $/ \mathrm{i} /$, and 310,870 , and $2250 \mathrm{~Hz}$ for $/ \mathrm{u} /$. Studies with synthetic speech sounds have demonstrated that a difference in the second formant alone is sufficient for perceptual identification of $/ \mathbf{i} /$ and $/ \mathbf{u} /$ (Delattre, Liberman, Cooper, \& Gerstman, 1952). In the latter study a two-formant stimulus with a first and second formant frequency of 270 and $2760 \mathrm{~Hz}$ was identified as $/ \mathrm{i} /$, whereas a stimulus with the same first formant frequency and second formant frequency of $720 \mathrm{~Hz}$ was identified as $/ \mathrm{u} /$. The pitch difference in the second formants is an acoustic correlate of the front to back shift in the articulation of $/ \mathrm{i} /$ and $/ \mathrm{u} /$. Although the frequency of vowel formants varies from speaker to speaker (Peterson \& Banney, 1952) and is affected within speakers by such factors as consonantal context and speaking rate (Miller, 1981), relative differences in formant frequencies among vowels seems to be a fundamental acoustic and perceptual phenomenon.

2. The mean value in each of the 96 cells of this ANOVA weighted the number of observations for each of the two signal-response combinations that contributed to it. The values depicted in Figure 1 are based on these means. The mean value in each of the 192 cells of the first ANOVA did not take account of the number of observations for each of the two signal-response combinations that contributed to it.

3. When the mean RTs were fitted by a linear function (of sequence length), both the zero intercept and the linear coefficient were highly significant ( $p<.001$ and $p<.02$, respectively), but when the mean RTs were fitted by a quadratic function, the zero intercept was significant $(p<.001)$, but neither the linear coefficient $(p=.84)$ nor the quadratic coefficient ( $p=.57$ ) was. This outcome replicates the finding of Sternberg et al. (1978) that, within the range of lengths they studied (which subsumes the range of lengths studied here), initiation time increased linearly but not quadratically with sequence length.

(Manuscript received March 6, 1986; revision accepted for publication October $20,1986$. ) 